\title{
Preoperative Delays in the Treatment of DCIS and the Associated Incidence of Invasive Breast Cancer
}

\author{
William H. Ward, MD, MS', Lyudmila DeMora, $\mathrm{MS}^{2}$, Elizabeth Handorf, $\mathrm{PhD}^{2}$, Elin R. Sigurdson, $\mathrm{MD}$, $\mathrm{PhD}^{3}$, \\ Eric A. Ross, PhD, ScM ${ }^{2}$, John M. Daly, $\mathrm{MD}^{3}$, Allison A. Aggon, $\mathrm{DO}^{3}$, and Richard J. Bleicher, $\mathrm{MD}^{3}$ \\ ${ }^{1}$ Department of Surgery, Naval Medical Center, Portsmouth, VA; ${ }^{2}$ Biostatistics and Bioinformatics Facility, Fox Chase \\ Cancer Center, Philadelphia, PA; ${ }^{3}$ Department of Surgical Oncology, Fox Chase Cancer Center, Philadelphia, PA
}

\begin{abstract}
Background. Although treatment delays have been associated with survival impairment for invasive breast cancer, this has not been thoroughly investigated for ductal carcinoma in situ (DCIS). With trials underway to assess whether DCIS can remain unresected, this study was performed to determine whether longer times to surgery are associated with survival impairment or increased invasion. Methods. A population-based study of prospectively collected national data derived from women with a clinical diagnosis of DCIS between 2004 and 2014 was conducted using the National Cancer Database. Overall survival (OS) and presence of invasion were assessed as functions of time by evaluating five intervals $(\leq 30,31-60,61-90,91-120$, 121-365 days) between diagnosis and surgery. Subset analyses assessed those having pathologic DCIS versus invasive cancer on final pathology.
\end{abstract}

Results. Among 140,615 clinical DCIS patients, 123,947 had pathologic diagnosis of DCIS and 16,668 had invasive ductal carcinoma. For all patients, 5-year OS was $95.8 \%$

Dr. Ward is a military service member. This work was prepared as part of his official duties. The views expressed in this article are those of the authors and do not necessarily reflect the official policy or position of the Department of the Navy, Department of Defense, or the United States Government.

Electronic supplementary material The online version of this article (https://doi.org/10.1245/s10434-019-07844-4) contains supplementary material, which is available to authorized users.

(C) The Author(s) 2019

First Received: 24 January 2019; Published Online: 27 September 2019

R. J. Bleicher, MD

e-mail: richard.bleicher@fccc.edu and unadjusted median delay from diagnosis to surgery was 38 days. With each delay interval increase, added relative risk of death was $7.4 \%$ (HR 1.07; 95\% CI 1.05-1.10; $P<0.001)$. On final pathology, 5-year OS for noninvasive patients was $96.0 \%$ (95\% CI 95.9-96.1\%) versus $94.9 \%$ (95\% CI 94.6-95.3\%) for invasive patients. Increasing delay to surgery was an independent predictor of invasion (OR 1.13; 95\% CI 1.11-1.15; $P<0.001$ ).

Conclusions. Despite excellent OS for invasive and noninvasive cohorts, invasion was seen more frequently as delay increased. This suggests that DCIS trials evaluating nonoperative management, which represents infinite delay, require long term follow up to ensure outcomes are not compromised.

Ductal carcinoma in situ (DCIS) is a premalignant lesion composed of malignant mammary ductal epithelial cells that have not yet invaded the basement membrane, whose standard interventions have included lumpectomy and radiotherapy or total mastectomy alone, followed by endocrine therapy. ${ }^{1-5}$ Defined as American Joint Commission of Cancer (AJCC) Stage 0, patient outcomes following standard treatment are excellent, with 5-year survival typically $>95 \%$. $^{2,6-8}$

Recently, therapies for DCIS have been scrutinized, as current data suggest that $<50 \%$ of afflicted patients will develop invasive cancer without treatment. ${ }^{1,2,8}$ Additionally, although DCIS detection has increased over recent decades secondary to mammographic improvements, advanced stage distributions have not correspondingly declined, suggesting that screening may detect some DCIS that would remain subclinical., ${ }^{2,4-13}$ Many have 
consequently questioned whether current DCIS paradigms constitute gross overtreatment, exposing thousands of women to therapy-related morbidity unnecessarily., $3,7,14,15$

Data are limited about intervals between diagnosis and surgery for women undergoing operative resection of DCIS as there is for invasive disease. ${ }^{16,17}$ Although we have found decreases in both disease-free and overall survival (OS) with each 30-day delay between histologic diagnosis and definitive surgery for early stage breast carcinoma, data regarding delays to surgery in DCIS is extremely limited. ${ }^{16,18}$ This is relevant today, as quality measures examining delay intervals are being considered by accreditation bodies, and ongoing trials are evaluating nonoperative management, which represents infinite "delay" to surgery. ${ }^{19,20}$

By examining a large population-based dataset, it is possible to achieve sufficient power to investigate delays in DCIS, elucidating its behavior in two ways. The first investigates whether there is a delay-dependent decline in survival for clinical DCIS that is still pure DCIS on final pathology. The second determines the risk of invasion with increasing delay for those initially staged as DCIS but found on final pathology to have invasion. DCIS lesions that develop and do not develop invasion are cohorts with differing risks that we need to distinguish to clarify which lesions should be aggressively treated and which can be observed.

\section{MATERIALS AND METHODS}

This analysis of the National Cancer Database (NCDB) is exempt per the Fox Chase Cancer Center Institutional Review Board, and permission was granted from the American College of Surgeons. This is the only dataset of its size for the United States containing the clinical and pathologic staging fields required for analysis. Time intervals between diagnosis and surgery were analyzed continuously, but categorized in 30-day increments with the 121 to 365 interval collapsed into 1 group to maintain sufficient power; thus, intervals were assigned as $\leq 30$, $31-60,61-90,91-120$, and 121-365 days. Date of "definitive surgery" was used as the operative date unless this differed from "first surgery" (28.0\% of patients), where the latter was utilized as the operative date. A sensitivity analysis for survival was performed by removing patients with $>1$ surgery date. To afford a uniform starting point for all patients, time from surgery was used for OS, and a sensitivity analysis calculating survival from time of diagnosis was also performed.

The cohort was limited to women with Clinical Stage 0 disease. Patients were included if DCIS was their first malignancy, lumpectomy or mastectomy was performed, and diagnosis and any treatment were completed at the reporting facility. Patients transferring facilities between diagnosis and treatment were identified as having a "transfer of care". ${ }^{21}$ To identify postoperative patients with DCIS or invasive ductal histology, the 2015 ICD-O-3 SEER Site/Histology Validation List was used. ${ }^{22}$ eTable 1 lists included histology codes.

Patients having conflicts between ICD-O-3 histologic codes versus pathologic stage were excluded, as well as patients whose stage, diagnosis method, treatment order, or survival status was unknown. Women without surgery, having unknown surgical status, time to surgery $>1$ year or unknown, and treatment not conducted at the reporting facility also were excluded (Fig. 1).

Within the initial cohort, AJCC Pathologic Stage indicated noninvasive or invasive disease. The noninvasive cohort refers to patients having DCIS on biopsy that also was purely DCIS on final excision. The invasive cohort refers to patients who had DCIS on initial biopsy, but were found to have any extent of invasive ductal carcinoma on final excision. Pathologic diagnoses that did not include ductal histology or subtypes were excluded to remove incidentally found additional primaries, as were those with incomplete pathologic data and staging. Due to space constraints, statistical methods are detailed in the online supplement.

\section{RESULTS}

The 140,615 patients analyzed overall had a median follow up of 57.7 months, and $47.5 \%$ of patients had $\geq 60$ months of follow-up. Mean (SD) patient age was 58.6 (11.9) years, ranging 18-90. Postoperatively, 123,947 $(88.1 \%)$ remained pathologically DCIS, whereas 16,668 (11.9\%) were found to have invasive disease (Fig. 1).

\section{Overall Survival}

Five-year OS was 95.8\% (95\% CI 95.7-96.0\%). Following adjustment, greater time to surgery (TTS), with multiple other factors, was independently associated with poorer survival (eTable 2). A total of 39,364 (28.0\%) patients had $>1$ surgery date recorded. A sensitivity analysis (eTable 3) excluding these women from the adjusted analysis found surgical delay significantly associated with OS (HR 1.12; 95\% CI 1.09-1.16; $P<0.0001$ ).

There were 123,947 patients analyzed after excluding those with invasive disease. Mean (SD) age for these patients was 58.7 (11.9) years (range 18-90); 7422 (6.0\%) patients died, and adjusted 5-year OS was $96.0 \%$ (Fig. 2). Adjusted associations between analyzed variables and OS in patients with noninvasive disease are shown in eTable 4. 
FIG. 1 Cohort exclusion criteria. Numbers represent remaining patients after that set of exclusions. AJCC American Joint Committee on Cancer; $B C T$ breast conservation therapy; DCIS ductal carcinoma in situ; $I D C$ invasive ductal carcinoma

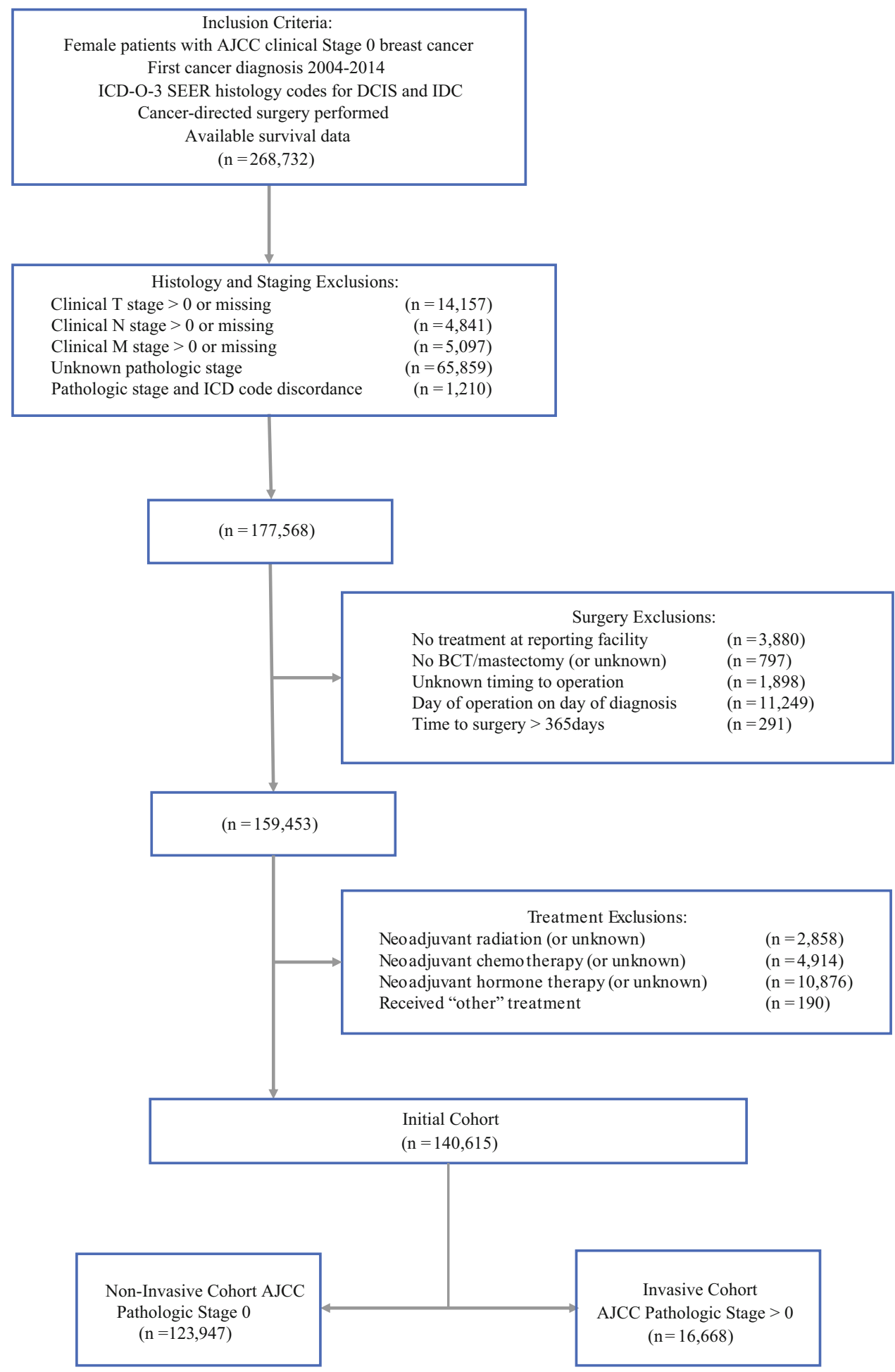

Among the 16,668 patients found postoperatively to have invasion, mean (SD) age was 57.3 (12.4) years (range 19-90). Within this cohort, $2730(16.4 \%)$ patients died and the adjusted 5-year OS was $94.9 \%$ (Fig. 2). eTable 5 demonstrates the adjusted associations between analyzed variables and $O S$ in patients with invasion.
Delay to Surgery

Unadjusted median delay from diagnosis to surgery was 38 (IQR: 24-58) days. Patients with intervals of $\leq 30$, $31-60, \quad 61-90, \quad 91-120, \quad 121-180, \quad 181-240$, and 241-365 days accounted for $37.6 \%, 38.9 \%, 14.6 \%, 5.2 \%$, 
FIG. 2 Overall survival of DCIS patients with invasive (blue line) and noninvasive (red line) disease identified on final pathology. $C I$ confidence interval; DCIS ductal carcinoma in situ

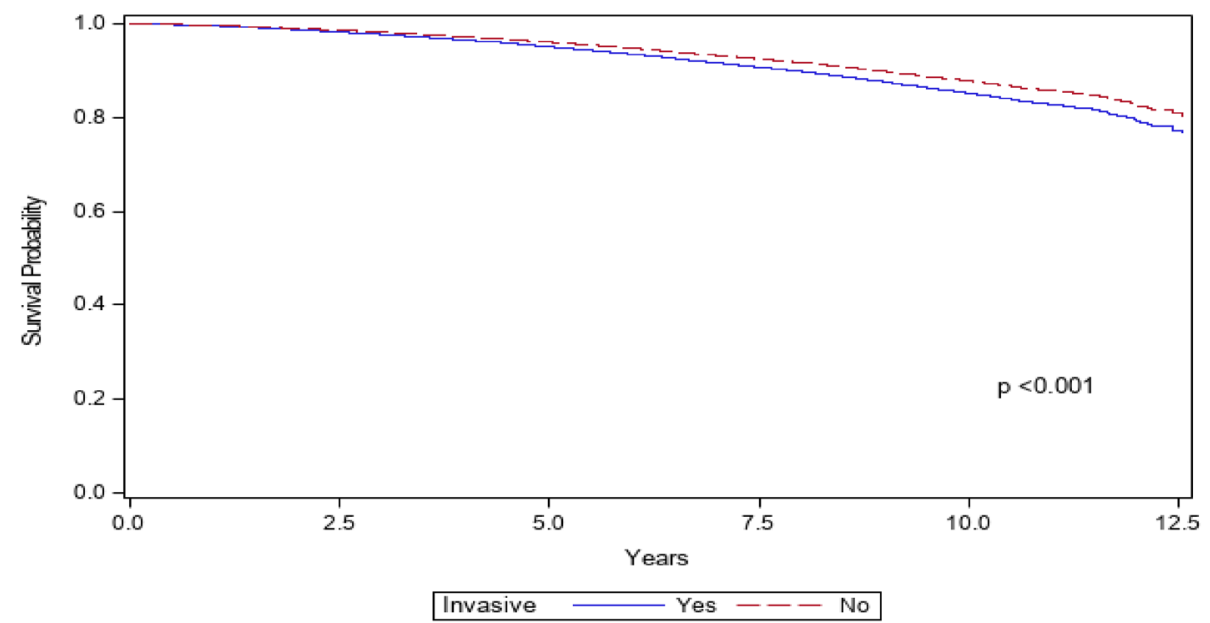

$\begin{array}{cc}\begin{array}{c}\text { Number of } \\ \text { Patients }\end{array} & \text { Invasive } \\ 2730 & \text { Yes } \\ 7422 & \text { No }\end{array}$

$2.8 \%, 0.6 \%$, and $0.3 \%$ of the total number, respectively. Patient characteristics are summarized by preoperative interval in eTable 6. After adjustment, characteristics independently associated with increased TTS included Black and Asian race, Hispanic ethnicity, lack of high school diploma, metropolitan setting, greater treating facility distance, transfers of care, and increased Charlson comorbidity score, among others (Table 1). Added risk of death from all causes for each 30-day interval delay increase was $7.4 \%$ (HR 1.07; 95\% CI 1.05-1.10; $P<0.0001)$ for the entire cohort. Survival point estimates by delay group are listed in eFig. 1 and eTable 7 .

Among those without invasion, individuals with intervals of $\leq 30,31-60,61-90,91-120,121-180,181-240$, and $241-365$ days accounted for $38.7 \%, 38.6 \%, 14.1 \%$, $5.0 \%, 2.6 \%, 0.6 \%$, and $0.3 \%$ of the cohort, respectively. The added risk of death from all causes for each 30-day interval increase in delay among the noninvasive cohort was $7.3 \%$ (HR $1.07 ; 95 \%$ CI 1.05-1.10; $P<0.0001$ ) (eTable 4).

Among the invasive patients, the progressive delay categories accounted for $28.8 \%, 41.0 \%, 18.5 \%, 6.8 \%$, $3.8 \%, 0.7 \%$, and $0.4 \%$ of the cohort, respectively. The added risk of death from all causes for each 30-day interval increase in delay among the invasive cohort was $6.8 \%$ (HR 1.07; 95\% CI 1.01-1.13; $P=0.0306$; eTable 5).

\section{Invasion}

As shown in Fig. 3 and Table 2, invasive cancer was increasingly found with greater delay, as well as associated

$\begin{array}{ccc}\text { Year } & \begin{array}{c}\text { Survival } \\ \text { Probability }\end{array} & \begin{array}{c}\text { Standard } \\ \text { Error }\end{array} \\ 5.0017 & 0.94933 & 0.001841 \\ 5.0017 & 0.96004 & 0.000672\end{array}$

$95 \% \mathrm{Cl}$

$0.94573,0.95295$

$0.95873,0.96136$ with insurance status, facility distance and volume, transfers of care, year of diagnosis, comorbidities, grade, and ER status. After adjustment, increasing delay to surgery in the entire cohort was an independent predictor of invasion (OR 1.13; 95\% CI 1.10-1.15; $P<0.001$ ). Among patients with postoperative diagnosis of invasive disease, median invasion measured $5.0 \mathrm{~mm}$ (range 0-480). Additional independent predictors of invasion are elaborated in Table 2. A sensitivity analysis in which women having $>1$ surgery date were excluded from the adjusted analysis (eTable 8) found that increasing delay to surgery remained an independent predictor of invasion (OR 1.12 per month delay; 95\% CI 1.10-1.15; $P<0.001)$. There was no significant difference in the survival effect from delay between women with or without invasion on pathology $(P=0.507)$.

\section{DISCUSSION}

Before 1980, DCIS was a rare diagnosis, comprising $<5 \%$ of identified breast cancers. ${ }^{23}$ Imaging and pathology advances have since increased the diagnosed frequency of DCIS, which now accounts for $25 \%$ of breast cancers in the United States. ${ }^{9}$ There has been evolution in treatment, which originally considered DCIS to be an expectant precursor to invasive disease. ${ }^{9,24,25}$ However, recent reports suggest that a significant number of in situ lesions are overtreated and may remain noninvasive and subclinical if observed. To our knowledge, this is the first investigation examining the association between delays to 
TABLE 1 Multivariable adjusted associations between patient characteristics and median delay to surgery

\begin{tabular}{|c|c|c|c|}
\hline Characteristic & $N(\%)$ & Median delay $(95 \% \mathrm{CI})$ & $P$ \\
\hline \multicolumn{4}{|l|}{ Age (years) } \\
\hline$<50$ & $35,662(25.4)$ & $40.45933(40.09947,40.81920)$ & \\
\hline $50-59$ & $40,490(28.8)$ & $39.15395(38.85004,39.45785)$ & $<0.001$ \\
\hline $60-69$ & $37,081(26.4)$ & $38.68148(38.39365,38.96932)$ & $<0.001$ \\
\hline$\geq 70$ & $27,382(19.5)$ & $37.55041(37.15215,37.94867)$ & $<0.001$ \\
\hline \multicolumn{4}{|l|}{ Race } \\
\hline White & $115,163(81.9)$ & $38.10018(37.93171,38.26865)$ & \\
\hline Black & $17,042(12.1)$ & $44.72110(44.20095,45.24124)$ & $<0.001$ \\
\hline Asian & $5769(4.1)$ & $40.91739(40.00678,41.82800)$ & $<0.001$ \\
\hline Other/unknown & $2641(1.9)$ & $39.69614(38.61258,40.77969)$ & 0.005 \\
\hline \multicolumn{4}{|l|}{ Ethnicity } \\
\hline Non-hispanic & $126,904(90.2)$ & $38.84077(38.67952,39.00202)$ & \\
\hline Hispanic & $7016(5.0)$ & $43.74860(42.84907,44.64812)$ & $<0.001$ \\
\hline Unknown & $6695(4.8)$ & $38.05353(37.43627,38.67080)$ & 0.015 \\
\hline \multicolumn{4}{|l|}{ Insurance } \\
\hline Medicaid & $6245(4.4)$ & $45.80981(44.92331,46.69630)$ & \\
\hline Medicare & $41,365(29.4)$ & $38.84621(38.49211,39.20031)$ & $<.001$ \\
\hline Uninsured & $2127(1.5)$ & $44.97280(43.32993,46.61567)$ & 0.371 \\
\hline Government & $1499(1.1)$ & $40.85378(39.23582,42.47175)$ & $<0.001$ \\
\hline Private & $87,763(62.4)$ & $38.43473(38.22994,38.63952)$ & $<0.001$ \\
\hline Unknown & $1616(1.1)$ & $41.92920(40.00933,43.84906)$ & $<0.001$ \\
\hline \multicolumn{4}{|l|}{ Education* } \\
\hline$>21 \%$ & $17,870(12.7)$ & $40.92560(40.40086,41.45033)$ & \\
\hline $13-20.9 \%$ & $31,550(22.4)$ & $39.49544(39.15450,39.83639)$ & $<0.001$ \\
\hline $7-12.9 \%$ & $46,629(33.2)$ & $39.16427(38.91023,39.41832)$ & $<0.001$ \\
\hline$<7 \%$ & $43,912(31.2)$ & $37.92761(37.60052,38.25470)$ & $<0.001$ \\
\hline Missing & $654(0.5)$ & $33.13101(26.41113,39.85090)$ & 0.025 \\
\hline \multicolumn{4}{|l|}{ Annual income } \\
\hline$<\$ 38,000$ & $18,831(13.4)$ & $37.83237(37.34633,38.31842)$ & \\
\hline$\$ 38,000-\$ 47,999$ & $27,816(19.8)$ & $38.53361(38.18661,38.88061)$ & 0.010 \\
\hline$\$ 48,000-\$ 62,999$ & $36,940(26.3)$ & $38.96734(38.66033,39.27435)$ & $<0.001$ \\
\hline$\geq \$ 63,000$ & $56,337(40.1)$ & $39.72927(39.41876,40.03977)$ & $<0.001$ \\
\hline Missing & $691(0.5)$ & $41.68427(35.49692,47.87162)$ & 0.225 \\
\hline \multicolumn{4}{|l|}{ Setting } \\
\hline Large metropolitan & $79,489(56.5)$ & $40.58126(40.36052,40.80200)$ & \\
\hline Small metropolitan & $40,922(29.1)$ & $37.45615(37.18598,37.72633)$ & $<0.001$ \\
\hline Suburban & $10,438(7.4)$ & $35.87115(35.29576,36.44654)$ & $<0.001$ \\
\hline Rural & $5869(4.2)$ & $33.77957(33.06795,34.49119)$ & $<0.001$ \\
\hline Unknown & $3897(2.8)$ & $40.93846(40.02934,41.84758)$ & 0.453 \\
\hline \multicolumn{4}{|c|}{ Distance to treatment facility (miles) } \\
\hline$\leq 10$ & $78,606(55.9)$ & $39.07204(38.85998,39.28410)$ & \\
\hline $11-20$ & $33,342(23.7)$ & $38.33902(38.03820,38.63984)$ & $<0.001$ \\
\hline $21-40$ & $16,577(11.8)$ & $38.51943(38.05730,38.98157)$ & 0.033 \\
\hline$>40$ & $11,360(8.1)$ & $41.64152(41.03239,42.25065)$ & $<0.001$ \\
\hline Unknown & $730(0.5)$ & $40.51603(37.60348,43.42858)$ & 0.334 \\
\hline \multicolumn{4}{|l|}{ Transfer of care } \\
\hline No & $86,170(61.3)$ & $37.54626(37.35774,37.73478)$ & \\
\hline Yes & $39,602(28.2)$ & $42.89649(42.55887,43.23410)$ & $<0.001$ \\
\hline
\end{tabular}


TABLE 1 continued

\begin{tabular}{|c|c|c|c|}
\hline Characteristic & $N(\%)$ & Median delay $(95 \% \mathrm{CI})$ & $P$ \\
\hline Unknown & $14,843(10.6)$ & $37.49980(37.09325,37.90635)$ & 0.837 \\
\hline \multicolumn{4}{|l|}{ Treatment facility annual volume } \\
\hline 0-17 patients (1st quartile) & $8131(5.8)$ & $36.38818(35.79152,36.98483)$ & \\
\hline 18-34 patients (2nd quartile) & $18,054(12.8)$ & $36.89268(36.48508,37.30028)$ & 0.156 \\
\hline 35-67 patients (3rd quartile) & $35,074(24.9)$ & $38.30192(38.01514,38.58870)$ & $<0.001$ \\
\hline$>67$ patients (4th quartile) & $79356(56.4)$ & $40.14092(39.93916,40.34269)$ & $<0.001$ \\
\hline \multicolumn{4}{|l|}{ Charlson Comorbidity Index } \\
\hline 0 & $120,676(85.8)$ & $38.97912(38.81081,39.14743)$ & \\
\hline 1 & $16,780(11.9)$ & $39.19972(38.75693,39.64252)$ & 0.354 \\
\hline 2 & $2659(1.9)$ & $40.20887(39.13911,41.27863)$ & 0.027 \\
\hline$\geq 3$ & $500(0.4)$ & $44.45383(42.02711,46.88056)$ & $<0.001$ \\
\hline \multicolumn{4}{|l|}{ Grade } \\
\hline Well differentiated & $17,357(12.3)$ & $39.70864(39.32554,40.09175)$ & \\
\hline Moderately differentiated & $47,300(33.6)$ & $39.57077(39.31976,39.82178)$ & 0.547 \\
\hline Poorly differentiated & $47,039(33.5)$ & $38.43289(38.16999,38.69579)$ & $<0.001$ \\
\hline Undifferentiated/anaplastic & $3684(2.6)$ & $38.67013(37.56746,39.77279)$ & 0.074 \\
\hline Unknown & $25,235(17.9)$ & $38.81639(38.46441,39.16837)$ & 0.001 \\
\hline \multicolumn{4}{|l|}{ Surgery type } \\
\hline Breast conservation & $89,156(63.4)$ & $34.06873(33.85780,34.27965)$ & \\
\hline Mastectomy & $24,905(17.7)$ & $42.65004(42.18069,43.11938)$ & $<0.001$ \\
\hline Mastectomy with reconstruction & $26,554(18.9)$ & $52.38859(51.89025,52.88693)$ & $<0.001$ \\
\hline \multicolumn{4}{|l|}{ Receipt of radiation } \\
\hline Yes & $70,069(49.8)$ & $38.59995(38.34745,38.85245)$ & \\
\hline No & $70546(50.2)$ & $39.49335(39.24647,39.74022)$ & $<0.001$ \\
\hline \multicolumn{4}{|l|}{ Receipt of endocrine therapy } \\
\hline Yes & $54,734(38.9)$ & $38.41799(38.17619,38.65979)$ & \\
\hline No & $85,881(61.1)$ & $39.44978(39.25416,39.64541)$ & $<0.001$ \\
\hline \multicolumn{4}{|l|}{ Year of diagnosis } \\
\hline 2004 & $4758(3.4)$ & $34.67071(33.92166,35.41976)$ & \\
\hline 2005 & $5318(3.8)$ & $35.42238(34.62557,36.21918)$ & 0.175 \\
\hline 2006 & $6238(4.4)$ & $35.81412(35.11195,36.51630)$ & 0.029 \\
\hline 2007 & $7444(5.3)$ & $38.54941(37.88847,39.21035)$ & $<0.001$ \\
\hline 2008 & $12,363(8.8)$ & $39.08158(38.55450,39.60865)$ & $<0.001$ \\
\hline 2009 & $14,713(10.5)$ & $38.80714(38.36663,39.24766)$ & $<0.001$ \\
\hline 2010 & $15,636(11.1)$ & $38.51970(38.06289,38.97650)$ & $<0.001$ \\
\hline 2011 & $16,954(12.1)$ & $38.85152(38.44292,39.26013)$ & $<0.001$ \\
\hline 2012 & $18,320(13.0)$ & $39.64301(39.25723,40.02878)$ & $<0.001$ \\
\hline 2013 & $19,626(14.0)$ & $40.41720(40.03274,40.80166)$ & $<0.001$ \\
\hline 2014 & $19,245(13.7)$ & $41.17652(40.76929,41.58375)$ & $<0.001$ \\
\hline
\end{tabular}

CI confidence interval; $O R$ odds ratio; Ref reference group

*Percent of adults without a high school diploma by zip code

surgery for DCIS and the presence of invasive disease, and OS, using a large, national, dataset while controlling for confounders through propensity weighting.

As expected, our data confirm that the vast majority of patients with DCIS who undergo surgical extirpation do so in less than 2 months (eFig. 2). We hypothesized that no outcome differences would be observed with longer times to surgery but found that surgical delay was indeed associated with lower OS, and as delay increased, invasion was increasingly found upon excision.

Greater risk of invasion with advancing delay in treating DCIS may be consistent with the fact that at least some DCIS is considered to be a precursor through which neoplastic ductal cells are present but have not yet violated the 
FIG. 3 Adjusted proportion of invasion by delay interval. Bars represent the percentage of patients with invasive disease as time to surgery increases $(P<0.0001)$

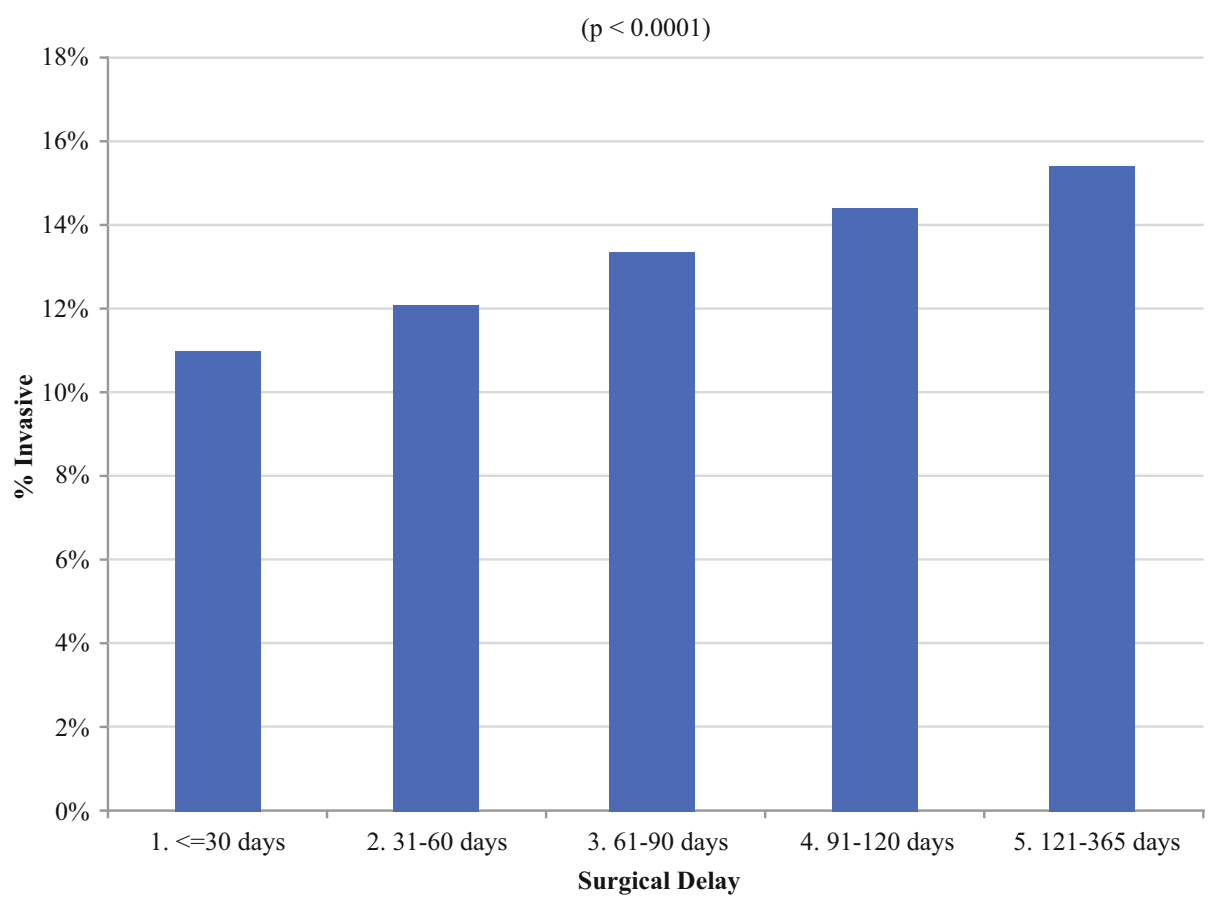

basement membrane. It should be noted, however, that with any study where DCIS is diagnosed on core biopsy, sampling error for the presence of invasion can occur, and time of transition from DCIS to invasive disease is impossible to determine. Our group previously demonstrated that women with early-stage breast cancer have worse outcomes as TTS increases, suggesting that sufficient time allows tumor growth and spread, conferring poorer outcomes. ${ }^{18}$ It also is not surprising that women experiencing disparities are more likely to experience greater delay and worsened outcomes. We saw such disparities, where race, insurance status, and education were associated with longer TTS.

We observed that survival differences over time between invasive and noninvasive cohorts remained clinically small in the short term (e.g., approximately $1 \%$ at 5 years), consistent with other data where invasive disease is minimal. ${ }^{26}$ However, our findings suggest that invasion is more frequently found as delay to surgery increases, suggesting that long-term delay or nonoperative management may have a significant impact on OS. When grouped by TTS, we observed OS differences varying, with earlier declines in OS observed in women who experienced delays greater than 6 months compared with those with shorter TTS (eFig. 1). The small OS differences seen between Stage 0 pathology and those diagnosed with minimal invasive disease may be explained by the fact that not all invasion is identified on final pathology. This also may be why we see a decline in OS with delay, even for "pure" DCIS. Prior studies reported $0-6 \%$ incidence of nodal metastases discovered in the setting of pTis postoperative histology, which is lower than the $13-50 \%$ sampling error rate associated with preoperative core needle biopsy, and is attributed to occult invasion. ${ }^{27-33}$ Additionally, the number of women who were found to have invasive cancer postoperatively was comparatively small, so the interaction test between delay and pathologic diagnosis of invasion may have had low power. Our survival data suggest that at least some DCIS lesions having no invasive foci identified may be similar to those having small invasive foci identified. This underscores the need to determine definitively which DCIS is truly noninvasive and remains so, posing little risk to the patient.

Questions regarding the extent or overall need for resection of DCIS in North America and Europe have prompted several clinical trials. Designed to clarify whether surgery can be eliminated while solely using endocrine therapy and close observation for low-risk DCIS, the COMET study is an ongoing, phase III, randomized, clinical trial enrolling in the United States. ${ }^{34}$ A similar European investigation randomizing women with DCIS to standard surgical-based care or mammographic observation has begun as the LORIS trial. ${ }^{35}$ The LORD study features a similar clinical design through which women with low-risk disease are randomized to either standard surgical-based treatment or surveillance alone. ${ }^{36}$ Given the debate regarding appropriate treatment of DCIS, the results of these multicenter trials will be extremely valuable. Our data demonstrate that delays to surgery portend worse outcomes, suggesting that nonoperative management may increase risk for DCIS patients when controlling for confounders. Until prospective, randomized data are available, our data do not yet support a change in the standard of care, 
TABLE 2 Multivariable adjusted associations between patient characteristics and invasion

\begin{tabular}{|c|c|c|c|}
\hline Characteristic & $N(\%)$ & OR $(95 \%$ CI $)$ & $P$ \\
\hline Delay from diagnosis to surgery (30-day interval $)^{\S}$ & $140,615(100)$ & $1.129(1.110,1.148)$ & $<0.0001$ \\
\hline \multicolumn{4}{|l|}{ Age $(\text { years })^{\S}$} \\
\hline$<50$ & $35,662(25.4)$ & Ref & \multirow[t]{4}{*}{$<0.0001$} \\
\hline $50-59$ & $40,490(28.8)$ & $0.807(0.773,0.842)$ & \\
\hline $60-69$ & $37,081(26.4)$ & $0.761(0.724,0.800)$ & \\
\hline$\geq 70$ & $27,382(19.5)$ & $0.737(0.689,0.787)$ & \\
\hline \multicolumn{4}{|l|}{ Race } \\
\hline White & $115,163(81.9)$ & Ref & \multirow[t]{4}{*}{0.1205} \\
\hline Black & $17,042(12.1)$ & $1.021(0.955,1.091)$ & \\
\hline Asian & $5769(4.1)$ & $0.987(0.895,1.088)$ & \\
\hline Other/unknown & $2641(1.9)$ & $0.850(0.739,0.977)$ & \\
\hline \multicolumn{4}{|l|}{ Ethnicity } \\
\hline Non-hispanic & $126,904(90.2)$ & Ref & \multirow[t]{3}{*}{0.0898} \\
\hline Hispanic & $7016(5.0)$ & $1.020(0.934,1.114)$ & \\
\hline Unknown & $6695(4.8)$ & $0.874(0.767,0.995)$ & \\
\hline \multicolumn{4}{|l|}{ Insurance } \\
\hline Private & $87,763(62.4)$ & Ref & \multirow[t]{6}{*}{0.0150} \\
\hline Medicaid & $6245(4.4)$ & $1.135(1.047,1.230)$ & \\
\hline Medicare & $41,365(29.4)$ & $0.974(0.922,1.030)$ & \\
\hline Uninsured & $2127(1.5)$ & $1.026(0.891,1.182)$ & \\
\hline Government & $1499(1.1)$ & $0.989(0.847,1.154)$ & \\
\hline Unknown & $1616(1.1)$ & $0.780(0.606,1.003)$ & \\
\hline \multicolumn{4}{|l|}{ Education* } \\
\hline$>21 \%$ & $17,87012.7 \%$ & Ref & \multirow[t]{5}{*}{0.1789} \\
\hline $13-20.9 \%$ & $31,55022.4 \%$ & $0.962(0.893,1.037)$ & \\
\hline $7-12.9 \%$ & $46,62933.2 \%$ & $1.017(0.937,1.105)$ & \\
\hline$<7 \%$ & $4391231.2 \%$ & $1.056(0.957,1.164)$ & \\
\hline Missing & $6540.5 \%$ & $0.795(0.275,2.300)$ & \\
\hline \multicolumn{4}{|l|}{ Annual income } \\
\hline$<\$ 38,000$ & $18,831(13.4)$ & Ref & \multirow[t]{5}{*}{0.1761} \\
\hline$\$ 38,000-\$ 47,999$ & $27,816(19.8)$ & $1.083(1.004,1.168)$ & \\
\hline$\$ 48,000-\$ 62,999$ & $36,940(26.3)$ & $1.086(0.997,1.183)$ & \\
\hline$\geq \$ 63,000$ & $56,337(40.1)$ & $1.064(0.954,1.186)$ & \\
\hline Missing & $691(0.5)$ & $1.704(0.700,4.148)$ & \\
\hline \multicolumn{4}{|l|}{ Setting } \\
\hline Large metropolitan & $79,489(56.5)$ & Ref & \multirow[t]{5}{*}{0.0949} \\
\hline Small metropolitan & $40,922(29.1)$ & $0.912(0.839,0.991)$ & \\
\hline Suburban & $10,438(7.4)$ & $0.963(0.864,1.075)$ & \\
\hline Rural & $5869(4.2)$ & $0.912(0.803,1.035)$ & \\
\hline Unknown & $3897(2.8)$ & $1.071(0.940,1.220)$ & \\
\hline \multicolumn{4}{|l|}{ Distance to treatment facility (miles) } \\
\hline$\leq 10$ & $78,606(55.9)$ & Ref & \multirow[t]{5}{*}{0.0008} \\
\hline $11-20$ & $33,342(23.7)$ & $1.010(0.964,1.058)$ & \\
\hline $21-40$ & $16,577(11.8)$ & $1.098(1.021,1.181)$ & \\
\hline$>40$ & $11,360(8.1)$ & $1.243(1.133,1.363)$ & \\
\hline Unknown & $730(0.5)$ & $0.668(0.349,1.279)$ & \\
\hline
\end{tabular}


TABLE 2 continued

\begin{tabular}{|c|c|c|c|}
\hline Characteristic & $N(\%)$ & OR $(95 \% \mathrm{CI})$ & $P$ \\
\hline \multicolumn{4}{|l|}{ Transfer of care } \\
\hline No & $86,170(61.3)$ & Ref & \multirow[t]{3}{*}{$<0.000$} \\
\hline Yes & $39,602(28.2)$ & $1.234(1.159,1.315)$ & \\
\hline Unknown & $14,843(10.6)$ & $1.079(0.995,1.170)$ & \\
\hline \multicolumn{4}{|c|}{ Treatment facility annual volume } \\
\hline $0-17$ patients (1st quartile) & $8131(5.8)$ & Ref & \multirow[t]{4}{*}{0.0002} \\
\hline 18-34 patients ( 2 nd quartile) & $18,054(12.8)$ & $1.077(0.944,1.229)$ & \\
\hline 35-67 patients (3rd quartile) & $35,074(24.9)$ & $1.119(0.983,1.274)$ & \\
\hline$>67$ patients (4th quartile) & $79,356(56.4)$ & $1.268(1.122,1.434)$ & \\
\hline Year of diagnosis ${ }^{\S}$ & $140,615(100)$ & $1.052(1.038,1.065)$ & $<0.001$ \\
\hline \multicolumn{4}{|l|}{ Charlson Comorbidity Index } \\
\hline 0 & $120,676(85.8)$ & Ref & \multirow[t]{4}{*}{$<0.001$} \\
\hline 1 & $16,780(11.9)$ & $1.133(1.076,1.193)$ & \\
\hline 2 & $2659(1.9)$ & $1.279(1.139,1.437)$ & \\
\hline$\geq 3$ & $500(0.4)$ & $1.181(0.896,1.556)$ & \\
\hline \multicolumn{4}{|l|}{ Grade } \\
\hline Well differentiated & $17,357(12.3)$ & Ref & \multirow[t]{5}{*}{$<0.001$} \\
\hline Moderately differentiated & $47,300(33.6)$ & $0.534(0.505,0.566)$ & \\
\hline Poorly differentiated & $47,039(33.5)$ & $0.252(0.234,0.271)$ & \\
\hline Undifferentiated/anaplastic & $3684(2.6)$ & $0.083(0.065,0.105)$ & \\
\hline Unknown & $25,235(17.9)$ & $0.354(0.308,0.408)$ & \\
\hline \multicolumn{4}{|l|}{ Estrogen receptor status } \\
\hline Negative & $19,836(14.1)$ & Ref & \multirow[t]{3}{*}{$<0.001$} \\
\hline Positive & $107,305(76.3)$ & $0.386(0.366,0.407)$ & \\
\hline Unknown & $13,474(9.6)$ & $0.104(0.090,0.121)$ & \\
\hline
\end{tabular}

CI confidence interval; $O R$ odds ratio; Ref reference group

*Percent of adults without a high school diploma by zip code

${ }^{\S}$ Continuous variable

which involves excision for those who will tolerate it. We therefore advocate nonoperative management solely in the context of clinical trials at this time and advocate for enrollment in those trials because of the association of delay with both invasion and survival.

Our study has several strengths and potential limitations. Our use of a large, contemporary cohort provided sufficient sample size to analyze delays to surgery and outcomes, while maintaining cohort generalizability. Our data were adjusted for facility volume as a surrogate for institutional expertise, which could add unmeasured confounding. Finally, our use of propensity-weighting allowed analysis of time to surgery, pathologic invasiveness, and overall survival in the setting of clinical DCIS, controlling for both characteristics and nonrandom treatment assignment.

Like any retrospective series, our study may be subject to potential biases and unmeasured confounding. Although the NCDB is a well-established quality dataset, data are limited by how well it was coded. Similarly, although phenotype is prognostic and we included grade and receptor status among our covariates, other nonstandard features are not typically included in the NCDB for DCIS diagnoses (e.g., HER2 status) but might be considered when interpreting these data. ${ }^{37,38}$ Additionally, changes to ensure de-identification limited inclusion of certain covariates of interest (e.g., NCDB censors facility type and location for all patients $<40$ years). Finally, although the NCDB does not include disease-specific survival, OS remains a valid outcome, having the advantage of including competing mortality risks associated with therapy. These observations are important for our study; existing data have shown that while women with DCIS have better OS than the general population, they also have lower breast cancer-specific survival. ${ }^{39}$ The role of these competing risks versus disease-specific mortality will need to be explored through ongoing trials. 


\section{CONCLUSIONS}

In women with a clinical diagnosis of DCIS, greater delay to surgery is associated with lower OS. Although most women with DCIS undergo surgical extirpation within 2 months of diagnosis, longer time to surgery is associated with greater risk of finding invasion and should be limited. Although clinical trials are underway, this large-scale dataset suggests that delays in nonoperative management of DCIS are associated with invasion and slightly worse short-term outcomes and should not yet be pursued outside of a clinical trial in patients who will tolerate excision. At minimum, these findings also suggest the need for long-term follow-up in women who are observed and better prediction of which subset of DCIS will develop an invasive component.

ACKNOWLEDGEMENT This work was supported by United States Public Health Services Grant P30 CA006927 for analysis of the data via support of our biostatistics facility, and by generous private donor support from the Marlyn Fein Chapter of the Fox Chase Cancer Center Board of Associates, for analysis and interpretation of the data.

AUTHOR'S CONTRIBUTION RJB, WHW: conception and design; RJB: financial support; RJB: administrative support; RJB, WHW, LD: collection and assembly of data; RJB, WHW, LD, EH: data analysis and interpretation; WHW, LD, EH, ERS, EAR, JMD, AAA, RJB: manuscript writing. All authors read and approved the final manuscript.

DISCLOSURE The NCDB is a joint project of the Commission on Cancer of the American College of Surgeons and the American Cancer Society. The data used in the study are derived from a deidentified NCDB file. The American College of Surgeons and the Commission on Cancer have not verified and are not responsible for the analytic or statistical methodology employed, or the conclusions drawn from these data by the investigator. The authors report no conflicts of interest.

OPEN ACCESS This article is distributed under the terms of the Creative Commons Attribution 4.0 International License (http://crea tivecommons.org/licenses/by/4.0/), which permits unrestricted use, distribution, and reproduction in any medium, provided you give appropriate credit to the original author(s) and the source, provide a link to the Creative Commons license, and indicate if changes were made.

\section{REFERENCES}

1. Wiechmann L, Kuerer HM. The molecular journey from ductal carcinoma in situ to invasive breast cancer. Cancer. 2008;112(10):2130-42.

2. Elshof LE, Schmidt MK, Rutgers EJT, van Leeuwen FE, Wesseling J, Schaapveld M. Cause-specific mortality in a populationbased cohort of 9799 women treated for ductal carcinoma in situ. Ann Surg. 2018;267(5):952-8.

3. Martinez-Perez C, Turnbull AK, Ekatah GE, et al. Current treatment trends and the need for better predictive tools in the management of ductal carcinoma in situ of the breast. Cancer Treat Rev. 2017;55:163-72.

4. Groen EJ, Elshof LE, Visser LL, et al. Finding the balance between over- and under-treatment of ductal carcinoma in situ (DCIS). Breast (Edinburgh, Scotland). 2017;31:274-83.

5. Rastogi P, Wickerham DL, Geyer CE, Jr., Mamounas EP, Julian TB, Wolmark N. Milestone clinical trials of the National Surgical Adjuvant Breast and Bowel Project (NSABP). Chin Clin Oncol. 2017;6(1):7.

6. Amin MB, Byrd DR, Brookland RK, Washington MK. AJCC cancer staging manual, 8th edn. Springer, Berlin; 2016.

7. Barrio AV, Van Zee KJ. Controversies in the treatment of ductal carcinoma in situ. Annu Rev Med. 2017;68:197-211.

8. Kanbayashi C, Iwata H. Current approach and future perspective for ductal carcinoma in situ of the breast. Jpn J Clin Oncol. 2017;47(8):671-677.

9. Virnig BA, Tuttle TM, Shamliyan T, Kane RL. Ductal carcinoma in situ of the breast: a systematic review of incidence, treatment, and outcomes. J Natl Cancer Inst. 2010;102(3):170-8.

10. Park TS, Hwang ES. Current trends in the management of ductal carcinoma in situ. Oncology (Williston Park, NY). 2016;30(9):823-831.

11. Bleyer A, Welch HG. Effect of three decades of screening mammography on breast-cancer incidence. $N$ Engl J Med. 2012;367(21):1998-2005.

12. Ansaloni L, Catena F, Chattat R, et al. Risk factors and incidence of postoperative delirium in elderly patients after elective and emergency surgery. Br J Surg. 2010;97(2):273-80.

13. Welch HG, Black WC. Overdiagnosis in cancer. JNCI J Natl Cancer Inst. 2010;102(9):605-13.

14. Grimm LJ, Shelley Hwang E. Active surveillance for DCIS: the importance of selection criteria and monitoring. Ann Surg Oncol. 2016;23(13):4134-6.

15. Comparing treatment options for women with low-risk ductal carcinoma in situ (DCIS) - The COMET Study. 2017. Available at: https://www.pcori.org/research-results/2016/comparing-treat ment-options-women-low-risk-ductal-carcinoma-situ-dcis-\%E2 \%80\%93-comet. Accessed 16 Jan 2018.

16. Sue GR, Lannin DR, Killelea B, Tsangaris T, Chagpar AB. Does time to definitive treatment matter in patients with ductal carcinoma in situ? Am Surg. 2013;79(6):561-5.

17. Bleicher RJ, Ruth K, Sigurdson ER, et al. Preoperative delays in the US Medicare population with breast cancer. J Clin Oncol. 2012;30(36):4485-92.

18. Bleicher RJ, Ruth K, Sigurdson ER, et al. Time to surgery and breast cancer survival in the United States. JAMA Oncol. 2016;2(3):330-9.

19. NAPBC. NAPBC Standards Manual. 2014 Edition. Available at: https://www.facs.org/ /media/files/quality\%20programs/napbc/ 2014\%20napbc\%20standards\%20manual.ashx. Accessed $1 \mathrm{Sept}$ 2017.

20. COC. CoC Quality of Care Measures. March 2015. Available at: https://www.facs.org/quality-programs/cancer/ncdb/qualitymeasu res. Accessed 1 Sept 2017.

21. Bleicher RJ, Chang C, Wang CE, et al. Treatment delays from transfers of care and their impact on breast cancer quality measures. Breast Cancer Res Treat. 2018.

22. SEER. ICD-0-3 SEER Site/Histology Validation List. September 18, 2015. Available at: https://seer.cancer.gov/icd-o-3/sitetype.ic do3.d20150918.pdf. Accessed 1 Sept 2017.

23. Rosner D, Bedwani RN, Vana J, Baker HW, Murphy GP. Noninvasive breast carcinoma: results of a national survey by the American College of Surgeons. Ann Surg. 1980;192(2):139-47.

24. Dupont WD, Page DL. Risk factors for breast cancer in women with proliferative breast disease. $N$ Engl J Med. $1985 ; 312(3): 146-51$. 
25. Sumner WE, 3rd, Koniaris LG, Snell SE, et al. Results of 23,810 cases of ductal carcinoma in situ. Ann Surg Oncol. 2007;14(5):1638-43.

26. Mirza NQ, Vlastos G, Meric F, et al. Ductal carcinoma in situ: long-term results of breast-conserving therapy. Ann Surg Oncol. 2000;7(9):656-64.

27. van Roozendaal LM, Goorts B, Klinkert M, et al. Sentinel lymph node biopsy can be omitted in DCIS patients treated with breast conserving therapy. Breast Cancer Res Treat. 2016;156(3):517-25.

28. Francis AM, Haugen CE, Grimes LM, et al. Is sentinel lymph node dissection warranted for patients with a diagnosis of ductal carcinoma in situ? Ann Surg Oncol. 2015;22(13):4270-9.

29. Meretoja TJ, Heikkilä PS, Salmenkivi K, Leidenius MHK. Outcome of patients with ductal carcinoma in situ and sentinel node biopsy. Ann Surg Oncol. 2012;19(7):2345-51.

30. Intra M, Rotmensz N, Veronesi P, et al. Sentinel node biopsy is not a standard procedure in ductal carcinoma in situ of the breast: the experience of the European institute of oncology on 854 patients in 10 years. Ann Surg. 2008;247(2):315-9.

31. Miyake T, Shimazu K, Ohashi H, et al. Indication for sentinel lymph node biopsy for breast cancer when core biopsy shows ductal carcinoma in situ. Am J Surg. 2011;202(1):59-65.

32. El Hage Chehade H, Headon H, Wazir U, Abtar H, Kasem A, Mokbel K. Is sentinel lymph node biopsy indicated in patients with a diagnosis of ductal carcinoma in situ? A systematic literature review and meta-analysis. Am $J$ Surg. 2017;213(1):171-80.

33. Podoll MB, Reisenbichler ES, Roland L, Bruner A, Mizuguchi S, Sanders MAG. Feasibility of the less is more approach in treating low-risk ductal carcinoma in situ diagnosed on core needle biopsy: ten-year review of ductal carcinoma in situ upgraded to invasion at surgery. Arch Pathol Lab Med. 2018;42(9):1120-26.

34. Youngwirth LM, Boughey JC, Hwang ES. Surgery versus monitoring and endocrine therapy for low-risk DCIS: the COMET Trial. Bull Am Coll Surg. 2017;102(1):62-3.

35. Francis A, Thomas J, Fallowfield L, et al. Addressing overtreatment of screen detected DCIS; the LORIS trial. Eur J Cancer. 2015;51(16):2296-303.

36. Elshof LE, Tryfonidis K, Slaets L, et al. Feasibility of a prospective, randomised, open-label, international multicentre, phase III, non-inferiority trial to assess the safety of active surveillance for low risk ductal carcinoma in situ-the LORD study. Eur J Cancer. 2015;51(12):1497-510.

37. Lannin DR, Wang S. Are small breast cancers good because they are small or small because they are good? $N$ Engl J Med. 2017;376(23):2286-91.

38. Giuliano AE, Connolly JL, Edge SB, et al. Breast cancer-major changes in the American Joint Committee on Cancer eighth edition cancer staging manual. $C A$ Cancer $J$ Clin. 2017;67(4):290-303.

39. Ernster VL, Barclay J, Kerlikowske K, Wilkie H, Ballard-Barbash R. Mortality among women with ductal carcinoma in situ of the breast in the population-based surveillance, epidemiology and end results program. Arch Intern Med. 2000;160(7):953-8.

Publisher's Note Springer Nature remains neutral with regard to jurisdictional claims in published maps and institutional affiliations. 